\title{
A structural analysis of the group II intron active site and implications for the spliceosome
}

\author{
KEVIN S. KEATING, ${ }^{1}$ NAVTEJ TOOR, ${ }^{2,3,4}$ PHILIP S. PERLMAN, ${ }^{3}$ and ANNA MARIE PYLE ${ }^{2,3}$ \\ ${ }^{1}$ Program in Computational Biology and Bioinformatics, Yale University, New Haven, Connecticut 06520, USA \\ ${ }^{2}$ Department of Molecular Biophysics and Biochemistry, Yale University, New Haven, Connecticut 06520, USA \\ ${ }^{3}$ Howard Hughes Medical Institute, Chevy Chase, Maryland 20815, USA
}

\begin{abstract}
Group II introns are self-splicing, mobile genetic elements that have fundamentally influenced the organization of terrestrial genomes. These large ribozymes remain important for gene expression in almost all forms of bacteria and eukaryotes and they are believed to share a common ancestry with the eukaryotic spliceosome that is required for processing all nuclear pre-mRNAs. The three-dimensional structure of a group IIC intron was recently determined by X-ray crystallography, making it possible to visualize the active site and the elaborate network of tertiary interactions that stabilize the molecule. Here we describe the molecular features of the active site in detail and evaluate their correspondence with prior biochemical, genetic, and phylogenetic analyses on group II introns. In addition, we evaluate the structural significance of RNA motifs within the intron core, such as the major-groove triple helix and the domain 5 bulge. Having combined what is known about the group II intron core, we then compare it with known structural features of U6 snRNA in the eukaryotic spliceosome. This analysis leads to a set of predictions for the molecular structure of the spliceosomal active site.
\end{abstract}

Keywords: RNA splicing; RNA tertiary structure; crystallography; ribozyme; triple helix

\section{INTRODUCTION}

Group II introns are self-splicing RNAs and transposable elements that are found in almost every form of life on earth (Lehmann and Schmidt 2003; Lambowitz and Zimmerly 2004; Pyle and Lambowitz 2006). They are abundant in bacteria, are found in archaea, and are common throughout the eukaryal kingdom. In eukaryotes, they are particularly prevalent in the organellar genes of yeast, fungi, and plants, as they appear to have entered the eukaryal lineage through the early bacterial endosymbiont events from which cellular organelles originated (Rest and Mindell 2003). Group II introns are an important part of our past, present, and future. They are crucial to our biological past because their dispersion helped remodel the genomes of almost all terrestrial life forms (Mattick 1994; Mattick and Gagen 2001), introducing introns, retrotransposons, and creating

${ }^{4}$ Present address: Department of Biochemistry, University of California, San Diego, La Jolla, CA 92093-0332, USA.

Reprint requests to: Anna Marie Pyle, Department of Molecular Biophysics and Biochemistry, Yale University, Room 334A Bass Building, 266 Whitney Avenue, New Haven, CT 06520, USA; e-mail: anna.pyle@ yale.edu; fax: (203) 432-5316.

Article published online ahead of print. Article and publication date are at http://www.rnajournal.org/cgi/doi/10.1261/rna.1791310. new mechanisms for generating genomic diversity (Boeke 2003; Wheelan et al. 2005; Koonin 2006). As time passed, they appear to have evolved into new types of machines that are now central for gene expression, such as the eukaryotic spliceosome (Koonin 2006). Group II introns remain important to our present, because their splicing is critical for metabolism in diverse organisms and they continue to disperse themselves through intron mobility reactions (Lambowitz and Zimmerly 2004). For example, new strains of multidrug resistant bacteria have been found to contain mobile group II introns that migrated and brought along new genes in the process (Centron and Roy 2002). Finally, group II introns are likely to be important for our future, as we learn to harness their activities for applications in biotechnology and gene therapy (Jones et al. 2005).

Group II introns are composed of six domains, of which domain 5 (D5) is the most phylogenetically conserved (Figs. 1, 2A; Michel et al. 1989; Toor et al. 2001). It was clear that D5 was special from the very first report that classified group II introns as a distinct family of RNA molecules (Michel et al. 1982, 1989). Deletion and trans-splicing analyses demonstrated that D5 was the most important component in reactions catalyzed by these large ribozymes (Jarrell et al. 1988; Koch et al. 1992; Franzen et al. 1993; 


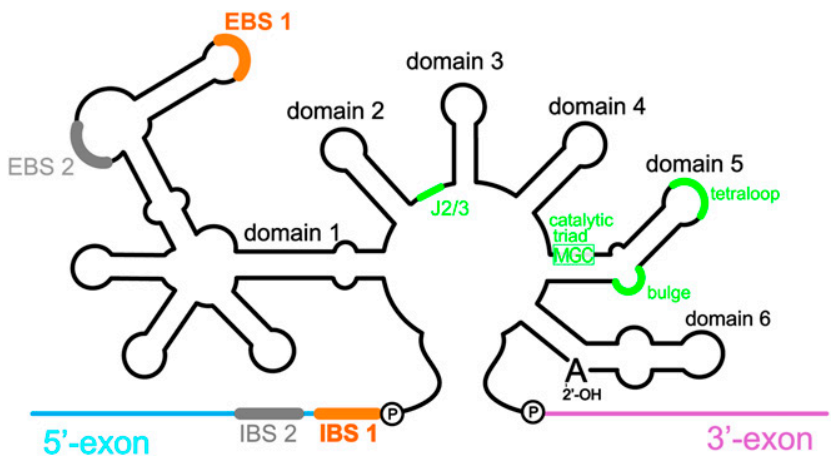

FIGURE 1. Schematic of a generic group II intron secondary structure. The six intron domains radiate from a central wheel. The EBS sequences in D1 recognize the $5^{\prime}$-exon through base-pairing interactions with the IBS sequences (note that the O.i. intron does not have EBS2-IBS2). D5 and its conserved components are highlighted in green. Note that the MGC sequence in the D5 catalytic triad ( $\mathrm{M}=\mathrm{A}$ or C) forms a triple helix with sequences in $\mathrm{J} 2 / 3$, also indicated in green.

Peebles et al. 1995). Mutational analysis and functional group studies showed that certain regions of D5 were particularly important and key tertiary interactions, including $\zeta-\zeta^{\prime}, \kappa-\kappa^{\prime}$, and $\lambda-\lambda^{\prime}$ were shown to link D5 with other regions of the intron (Lehmann and Schmidt 2003; Pyle and Lambowitz 2006). Almost every atom of D5 has been examined in detail, and in the course of these many studies, two major themes have emerged: (1) The atoms that are most important for chemical catalysis are located in the D5 bulge and in a set of three consecutive nucleotides that are located in D5 stem 1 (the so-called "catalytic triad," which is usually 5'-AGC) (Chanfreau and Jacquier 1994; Peebles et al. 1995; Abramovitz et al. 1996; Konforti et al. 1998; Gordon and Piccirilli 2001). (2) D5 looks and behaves a lot like U6 (Madhani and Guthrie 1992; Yu et al. 1995; Yean et al. 2000; Shukla and Padgett 2002), which is a conserved spliceosomal RNA that is implicated in catalysis during nuclear pre-mRNA splicing. Thus, the structure and function of D5 is a vital link to our understanding of splicing chemistry. It is also a vital link to the past and to a possible common ancestor between group II introns and the highly complex spliceosomal machinery.

The structure and function of D5 have now become significantly clarified by high resolution crystal structures of a group IIC intron from the eubacterium Oceanobacillus ihyensis (O.i.) (Keating et al. 2008; Toor et al. 2008a,b, 2009). These structures show that D5 is the center of an elaborate interaction network that joins the D5 bulge and catet al. 2010). alytic triad with conserved nucleotides of previously unknown function (Fig. 2). The interactions that support this network are highly unusual, and they include substructures that expand the known repertoire of RNA architectural motifs. But just as important, the interaction network provides a map that links the architectural components of group II introns with potential counterparts in the spliceosome. Here we examine the motifs that comprise the catalytic intron core and we evaluate their significance from a structural perspective. We then use the map of D5 interactions to explore a potential set of corresponding, hypothetical interactions within the spliceosome.

\section{Structural attributes of the catalytic triplex in D5}

One of the most striking features of the group II intron active site is the triple helix between D5 and nucleotides within the J2/3 linker (Figs. 2, 3; Toor et al. 2008a,b). This interaction merges two of the most functionally important elements of the group II intron and explains why they share such a high level of phylogenetic conservation (Michel et al. 1989; Toor et al. 2001; Lehmann and Schmidt 2003; Pyle and Lambowitz 2006): Despite their distance in primary sequence, D5 and J2/3 are drawn together as components of the same structural entity in the complete intron.

In addition to its significance for splicing catalysis, the structural attributes of the D5 triplex are inherently interesting. Most significantly, the constrained geometry of the A-form major groove does not preclude binding of a third strand. Triplex formation by D5 does not induce local B-form geometry or cause major distortions from
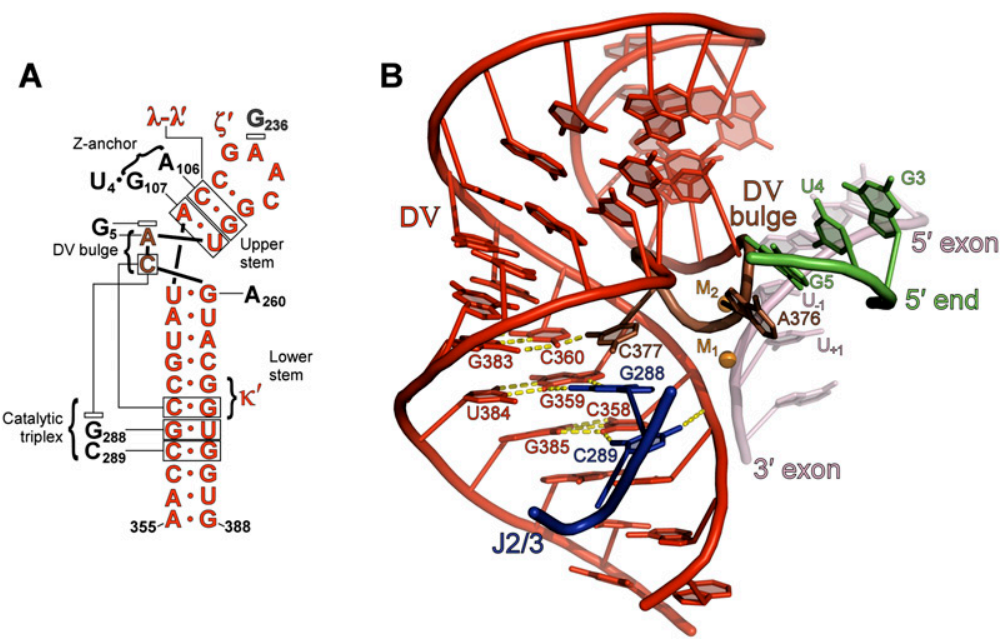

FIGURE 2. D5 structure showing interactions with other domains. (A) Secondary structure of D5. (B) Representation of the D5 tertiary structure. The catalytic bulge of D5 is shown in brown, while the rest of D5 is shown in red. The upstream terminus of the intron is shown in green and J2/3 is blue. Note that all group II intron structural analysis described in this paper was conducted on the refined model with pdb code 3EOH (Toor et al. 2008b). All interactions described and shown here are also present in the re-refined model with pdb code 3IGI (Toor 

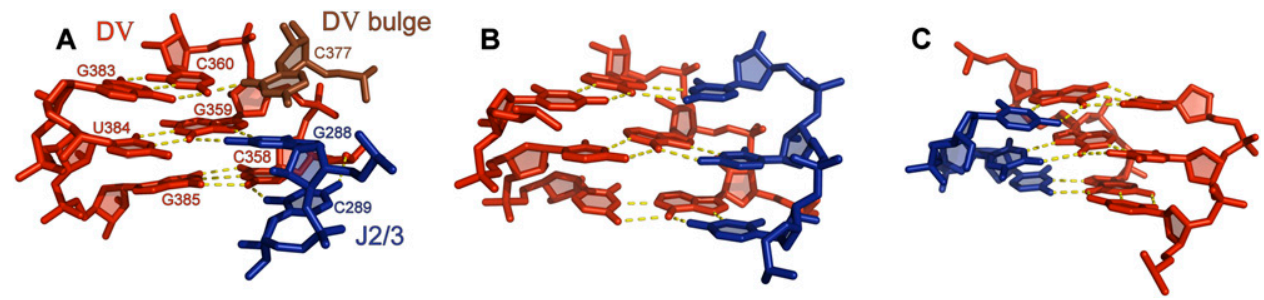

FIGURE 3. Major-groove triplexes in RNA and DNA: $(A)$ The catalytic triplex in D5. $(B)$ The major-groove RNA triplex from telomerase RNA (Kim et al. 2008). (C) A typical DNA triplex consisting of three stacks (Rhee et al. 1999). Sugar puckers in the group II intron structure were determined using the phosphate-glycosidic bond perpendicular distance (Davis et al. 2007; Murray 2007), which measures the distance from the glycosidic bond to the $3^{\prime}$ phosphate. A distance of greater than $2.9 \AA^{\circ}$ corresponds to a C3' endo sugar pucker. This distance is $3.2 \AA$ for C377, $3.5 \AA$ for C289, and greater than $4.4 \AA$ for all other triplex nucleotides, which indicates a C3' endo pucker in all cases.

standard A-form parameters of the duplex (Figs. 2, 3). Sugar puckers of the duplex nucleotides remain $\mathrm{C}^{\prime}$-endo and the only deviation that can be detected at this level of resolution is an expansion of the major-groove width by $2 \AA$, which appears to be accomplished by small local alterations in backbone torsion angles that cannot be definitively characterized at this level of resolution. At the widest point of its central region (the $\mathrm{G} \bullet \mathrm{G}-\mathrm{U}$ triple) (Figs. 3 , 4), the triplex is $\sim 21 \AA$ in width, which compares favorably with the major-groove triplex observed in the structure of telomerase RNA (Theimer et al. 2005), which is also composed of $\mathrm{C}^{\prime}$ endo nucleotides, has similar overall dimensions and minimal distortion of the duplex region (Fig. 3). Given the similarity in conformational features of the D5 and telomerase RNA triplexes, the major-groove RNA triplex is likely to represent a generalizable form of molecular recognition in RNA.

The individual base triple interactions share similarities and differences from triplexes previously reported for DNA (Fig. 4; Patel and Radhakrishnan 1994; Frank-Kamenetskii and Mirkin 1995; Gilbert and Feigon 1999). The most conventional triplet within the series is observed in the center of the motif, involving the invariant guanosine of the 5'CGC triad in D5 of O.i. (Fig. 4B). In this case, the thirdstrand guanosine (G288) maintains an anti-glycosidic conformation, and forms a reverse-Hoogsteen interaction with the major-groove edge of G359. This triple is flanked by two examples of a relatively unusual triplet involving third- strand cytosine nucleotides. For example, base pair C358G385 interacts with an incoming cytosine through a single contact between the exocycline amine of $\mathrm{C} 358$ and $\mathrm{O} 2$ of C289 (Fig. 4C), which is in the anti-conformation. This interaction appears to be buttressed by contact between the amine of C289 and an upstream phosphoryl oxygen of C358. A similar cytidine triple joins bulge nucleotide $\mathrm{C} 377$ with the C360-G383 base pair in D5. In this case, a single hydrogen bond joins the exocyclic amine of $\mathrm{C} 360$ and $\mathrm{O} 2$ of $\mathrm{C} 377$ (Fig. 4A). These findings suggest that the $\mathrm{C} \cdot \mathrm{C}-\mathrm{G}$ triple is a robust form of molecular recognition in RNA, which is supported by the observation of major-groove $\mathrm{C} \cdot \mathrm{C}-\mathrm{G}$ triplets in structures of the ribosome (pdb code 1S72) (Klein et al. 2004), such as C1940•C1943-G1895, C141•C143G135, and C1176•C1196-G1203. Triples were found using FR3D (Sarver et al. 2008). To our knowledge, this form of triple has not been observed in DNA, and may be favorable only in the context of RNA tertiary structures.

\section{Covariation between the catalytic triad and $\mathrm{J} 2 / 3$}

Given that the structure reveals triple helix formation between D5 and specific nucleotides in $\mathrm{J} 2 / 3$, it is now possible to interpret the significance of phylogenetic covariations between these domains. The catalytic triad of group IIC introns is a $5^{\prime}$-CGC sequence (Toor et al. 2001), while that of group IIB and group IIA introns is $5^{\prime}$-AGC (Michel et al. 1989). The central G of the triad (5'-A $\underline{\text { GC }}$ and
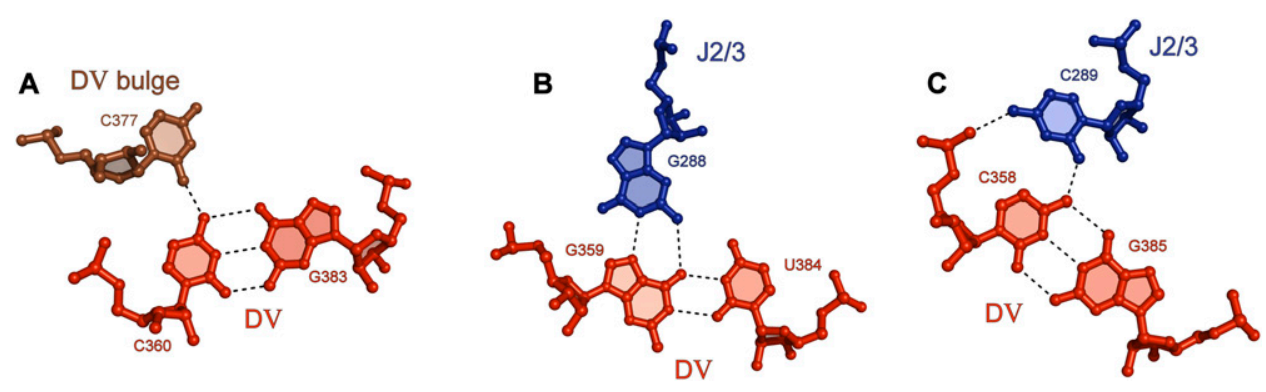

FIGURE 4. Base triples within the catalytic triplex. (A) Interaction between C377 of the DV bulge and C360-G383. (B) Interaction between G288 of J2/3 and C359-U384. (C) Interaction between C289 of J2/3 and C358-G385. 
$5^{\prime}$-CGC) is invariant, and its corresponding partner in $\mathrm{J} 2 / 3$ is also invariant, so covariation analysis cannot be applied. However, one can consider potential covariation for the first nucleotide of the triad (i.e., $5^{\prime}$ - $\underline{\mathbf{A}} \mathrm{GC}$ and $5^{\prime}$ - $\underline{\mathrm{CGC}}$ ). In group IIC introns, where the first nucleotide of the triad is a $\mathrm{C}$, the corresponding nucleotide in $\mathrm{J} 2 / 3$ is a $\mathrm{C}$ (Granlund et al. 2001; Toor et al. 2001) (which is located immediately downstream of the invariant G). In both group IIA and group IIB introns, where the first nucleotide of the triad is an $\mathrm{A}$, the corresponding nucleotide in $\mathrm{J} 2 / 3$ is an A (Fig. 4; Toor et al. 2001). When assisted by molecular modeling and guided by the structure, this leads to a clear prediction for the molecular architecture of triple base interactions in group IIB and IIA introns. When an A-U pair is modeled in the exact location of the corresponding C358-G385 pair in the crystal structure, and an adenine is substituted for the third strand C289, one observes facile steric accommodation by the active site and formation of a potentially stable triple interaction (Fig. 5A). The resulting model predicts that $\mathrm{N} 1$ and $\mathrm{N} 6$ moieties of the third-strand adenine are poised to interact with the N6 and N7 moieties, respectively, of the corresponding adenosine within D5 (Fig. 5B). Thus, the first two nucleotides of the catalytic triad in group IIA and IIB introns $\left(5^{\prime}-\underline{A G C}\right)$ are likely to form a triple interaction with the corresponding $\mathrm{J} 2 / 3$ region in those introns ( $\left.5^{\prime}-\mathrm{AGA}\right)$, which is significant because these sequences have spliceosomal analogs (vida infra).

\section{Structural attributes of the bulge}

The base pairing arrangement in the D5 bulge region is consistent with the revised prediction for D5 secondary structure (Konforti et al. 1998; Costa et al. 1998), which
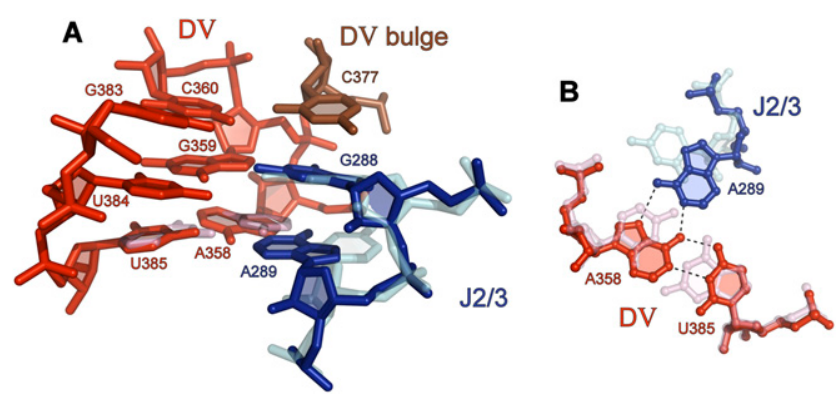

FIGURE 5. A model of the intron core containing the IIB consensus sequence for the catalytic triad ( $\left.5^{\prime}-\mathrm{AGC}\right)$ and J2/3 (5'-GA). (A) The IIC structure of D5 and J2/3 are shown in transparent pink and cyan, respectively, while the IIB model of D5 and J2/3 are shown in red and dark blue, respectively. (B) A view from the top of the first triple interaction of the triplex. The $\mathrm{A} \bullet \mathrm{A}-\mathrm{U}$ triple proposed for IIB introns is shown in bold, superimposed on the transparent $\mathrm{C} \cdot \mathrm{C}-\mathrm{G}$ triple observed in the IIC crystal structure. The IIB model was constructed starting from the IIC structure. Nucleotide bases were mutated and manually repositioned using Coot (Emsley and Cowtan 2004). Energy minimization was then carried out using CNS (Brünger et al. 1998). Minimization constraints for the $\mathrm{A} \bullet \mathrm{A}$ interaction were derived from structures found in the base pair isostericity database (Leontis et al. 2002). was derived from phylogenetic and biochemical analysis. According to this prediction, an extrahelical 5'-AC bulge should be flanked by a wobble $\mathrm{G}-\mathrm{U}$ pair in stem 1 and a $\mathrm{W}-\mathrm{C}$ pairing in stem 2 , which is exactly what is observed in the crystal structure (Fig. 6; Toor et al. 2008a,b).

As suggested by numerous biochemical studies (Chanfreau and Jacquier 1994; Peebles et al. 1995; Abramovitz et al. 1996; Konforti et al. 1998; Gordon and Piccirilli 2001), atoms of the sugar-phosphate backbone are involved in tertiary interactions and metal ion binding. In the structural context of the intron, the architecture of the bulge is different than reported in solution studies of D5 (Sigel et al. 2004) and in crystallographic studies of D5 in isolation (Zhang and Doudna 2002), although the latter was closer to the conformation observed within the intact intron.

In the crystal structure of the intron, the backbone strand of the bulge curls tightly upon itself, forming a highly unusual minihelix with a similar pitch to that seen in $\alpha$-helical peptide backbones (Fig. 2B). The constricted dimensions of this single-stranded region have not been observed previously in nucleic acids and a PRIMOS analysis of deposited structures (Duarte et al. 2003; Wadley et al. 2007) reveals it to be a novel substructure. Nearly all atoms of the nucleotides in this region are involved in critical aspects of intron function.

Bulge nucleotide A376 plays two roles in the structure: its backbone moieties coordinate a divalent metal ion that is implicated in catalysis and the nucleobase extends toward the platform created by parallel helices IC and I(i) (Toor et al. 2008a,b). Nucleobase A376 stacks on the highly conserved nucleotide G5, thereby helping to dock and orient the $5^{\prime}$-terminus of the intron. This finding is consistent with site-directed photocrosslinking studies on the ai5 $\gamma$ group IIB intron (DeLencastre et al. 2005), which displays high-efficiency crosslinks between the corresponding D5 bulge nucleotide A838 and G5. The parity of these results between IIC and IIB introns suggests that D5 bulge architecture and its role in catalytic function are similar across intron families.

Bulge nucleotide C377 extends into the major groove of D5 stem 1, where it forms a triple interaction with C360G383, thereby serving as the terminal stack of the catalytic triplex between D5 and J2/3. The structure explains the frequent phylogenetic variation of $\mathrm{C}$ to $\mathrm{U}$ at this position in the D5 bulge (and perhaps the almost invariant character of U74 at the analogous position in the U6 internal stem-loop, vida infra) (Griffiths-Jones et al. 2005; Davila Lopez et al. 2008): C377 interacts with C360 through the O2 ketone moiety. Uracil has a ketone at the identical position and can therefore interact in the same manner. The occasional observation of adenine at this position in D5 may be explained by the potential of $\mathrm{N} 3$ to form a similar type of interaction.

Immediately beneath the bulge is a wobble pairing between U365 and G378. The guanosine at this position 


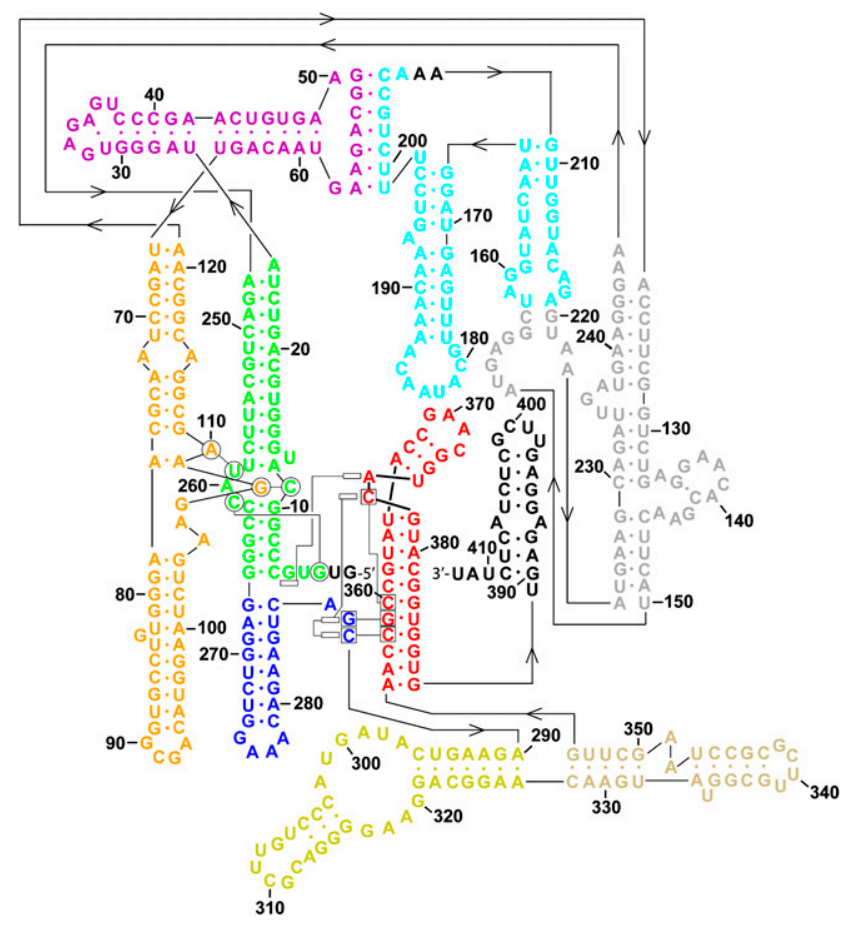

FIGURE 6. Revised secondary structure of the O.i. intron. Domains I(i) and I(ii) are shown in green, IA and IB in purple, IC in orange, ID1 in gray, ID2 in cyan, DII in blue, DIII in yellow, DIV in beige, DV in red, and DVI (which was not visualized in the crystal structure) in black. Tertiary base-pairing (shown as circles), base-triple (shown as squares), and base-stacking interactions (shown as rectangles) are displayed only for the core of the intron.

is almost invariant in group II introns, plays a highly important role in catalytic function and is common at the analogous position in the spliceosome (Griffiths-Jones et al. 2005; Davila Lopez et al. 2008). The striking conservation of G378 is explained by its pairing interaction with a conserved adenosine that is located in a common loop structure at the base of the D1 stem [loop I(i)] (Michel et al. 1989). The G378-A260 interaction is a classical sugar-edgeHoogsteen pairing, which explains the relative lack of covariation at these positions.

\section{DISCUSSION}

\section{The general significance of major-groove RNA triplexes}

The catalytic triplex within D5 is one of the first cases in which a major-groove triple helix has been reported for an RNA molecule (Theimer et al. 2005; Gilbert et al. 2008). By contrast, the binding affinity and specificity of majorgroove DNA triplexes has been studied for decades as a potential means for manipulating gene expression (Sun et al. 1996; Barre et al. 2000; Diviacco et al. 2001; Rogers et al. 2005) and as a hypothetical structural form that is believed to occur naturally in DNA regulatory regions
(Mirkin and Frank-Kamenetskii 1994; Frank-Kamenetskii and Mirkin 1995). Triple-stranded DNA structures occur so readily because the DNA major groove is wide and accessible for the binding of ligands. A third strand can easily enter the groove and interact through an extended network of Hoogsteen interactions with the major-groove edge of the B-form duplex (Saenger 1984).

Although the existence of triple-stranded RNA structures was suggested by early fiber diffraction patterns of homopolymers [such as poly(A) mixed with poly(U)] (Saenger 1984), the deep and narrow major groove of A-form RNA duplexes was thought to preclude extensive binding of large ligands and the formation of extended RNA triplexes, which instead were observed within the accessible RNA minor groove. High resolution evidence for major-groove RNA triplexes is now provided by three recent structures that showcase a diversity of architectural forms and triplet base combinations (Theimer et al. 2005; Gilbert et al. 2008; Toor et al. 2008a). Many of the constituent triplets have been observed as isolated interactions in structures of tRNA, the ribosome, and other molecules.

The triplex within group II intron D5 demonstrates that RNA duplexes can maintain an A-like geometry while accommodating a third strand in the major groove. Thus, an RNA duplex does not have to "become like DNA" in order to form a major-groove triplex. Many of these same concepts are apparent from the NMR structure of a telomerase RNA pseudoknot (Theimer et al. 2005). In that case, the RNA duplex is A-form and the nucleotides that interact with the third strand in the major groove retain the C3'-endo pucker conformation. The constituent triplets are conventional $\mathrm{U} \bullet \mathrm{A}-\mathrm{U}$ Hoogsteen interactions that are common DNA structural elements. More diversity in form is apparent in the structure of the SAM-II riboswitch (Gilbert et al. 2008), which diplays a distorted helical geometry in which the major groove has widened sufficiently to accommodate both a third strand and the binding of the S-adenosyl methionine ligand. As in the group II intron structure, the major-groove contacts formed by the third strand include both conventional and unusual triplets (Toor et al. 2008a). Taken together, these structures have significantly expanded the known repertoire of RNA molecular recognition strategies.

\section{Biochemical and genetic studies on function of the catalytic triplex}

Extensive biochemical and genetic studies have been conducted on the mechanistic role of atoms within the "AGC triad." Although that work was conducted primarily on the ai5 $\gamma$ group IIB intron (for review, see Lehmann and Schmidt 2003; Pyle and Lambowitz 2006), the data are strikingly consistent with structural features of the O.i. group IIC intron (Toor et al. 2008a), which strongly suggests that active-site elements are similar among all group II intron classes. 
One of the most puzzling results from in vitro and in vivo mutational studies of D5 was an asymmetry of mutational effects in D5 stem 1. Mutations of the conserved 5'-AGC-3' catalytic triad nucleotides result in severe splicing defects, while mutation of their pairing partners $\left(5^{\prime}-\mathrm{G}_{845} \mathrm{U}_{846} \mathrm{U}_{847}-3^{\prime}\right.$ on the opposite strand of ai5 $\gamma$ D5) caused minor defects both in vitro (Peebles et al. 1995) and in vivo (Boulanger et al. 1995). This makes sense in light of the structure because only the conserved $5^{\prime}$-AGC- $3^{\prime}$ nucleotides (and not their pairing partners) form hydrogen bonds with thirdstrand nucleotides of the triplex. One mutant in which a base pair of the triad is "flipped" $\left(A_{816}-U_{847}\right.$ to $\left.U_{816}-A_{847}\right)$ has nearly the wild-type level of splicing in vivo (Boulanger et al. 1995) and it may be explained by retention of the ability to maintain third-strand contact.

Genetic and phylogenetic studies have shown that the second two nucleotides of the triad ( $5^{\prime}$-A $\underline{\mathrm{GC}}$ ) are particularly sensitive to mutagenesis, and the guanosine is almost invariant. This suggests that the underlined residues of the triad (which are identical in the O.i. intron) play a more central role in the reaction mechanism of the intron. Again, this makes sense from the perspective of the structure, which shows that the second and third nucleotides of the triad tie that region to the D5 bulge and thereby create the catalytic metal ion binding site. This intimate involvement with metal ions is remarkably consistent with genetic studies showing that nuclear suppressor mutations in the MRS2 gene, which increases the level of a mitochondrial $\mathrm{Mg}^{2+}$ transporter, restores some splicing activity to yeast introns containing certain mutations in the catalytic triad (Schmidt et al. 1998; Gregan et al. 2001). Thus, in vivo splicing of introns that are defective in catalytic metal ion binding may be partially restored by increased mitochondrial $\mathrm{Mg}^{2+}$ concentrations.

The first triplet of the series appears to play a supporting role in stabilizing interactions with $\mathrm{J} 2 / 3$. One of the most striking mutational effects reported in the literature on group IIB introns is that the first base pair of the triad (A-U) can be changed to $\mathrm{C}-\mathrm{G}$ (subsequently shown to be the consensus for IIC introns) and the resulting mutant retains wild-type activity (Peebles et al. 1995), suggesting that 5 '-CGC may be functional in multiple contexts.

Chemogenetic studies on the chemical mechanism of D5 explored the role of individual atoms within the AGC triad. These studies, which differentiated effects on chemical catalysis from those on ground-state docking of D5, showed that any alteration of the guanosine major-groove edge (N6 and N7) eliminated the chemical step of reaction (Konforti et al. 1998). This is explained by the structure, which reveals a Hoogsteen interaction between the triad guanosine and the invariant $G$ within $\mathrm{J} 2 / 3$. Chemogenetic analyses also showed that a minor groove substituent of the triad guanosine (N2) has no role in reaction chemistry, but it thermodynamically stabilizes D5 docking (Konforti et al. 1998). Structurally, this may be explained by proximity between kappa nucleotides and the exocyclic amine of G359. The involvement of almost all guanosine atoms in molecular contacts may explain the extreme conservation of G359.

While the structure helps explain previous mutational results, the converse is true as well. For example, all five triad mutations that were tested in vivo are inactive for splicing in vivo. They were also inactive under one commonly used in vitro reaction condition that lacks $\left(\mathrm{NH}_{4}\right)_{2} \mathrm{SO}_{4}$, but all five had detectable self-splicing activity in a reaction medium containing 0.5 M ( $\left.\mathrm{NH}_{4}\right)_{2} \mathrm{SO}_{4}$ (Boulanger et al. 1995). Certain revertants of the triad mutants, and some revertants with nuclear suppressor mutations regain significant splicing activity in vivo and these are interesting because they do not display second-step defects (Boulanger et al. 1995; Schmidt et al. 1998). Given the role of J2/3 in formation of $\gamma-\gamma^{\prime}$ and recognition of the $3^{\prime}$-splice site, it has been suggested that $\mathrm{J} 2 / 3$ is important only in the second step of splicing (Mikheeva et al. 2000), which would imply a major active-site rearrangement between the first and second steps of splicing. The fact that revertants of triad mutants do not have second step defects (Boulanger et al. 1995; Schmidt et al. 1998) suggests that the catalytic triplex persists through both steps of splicing, which is consistent with site-directed crosslinking studies (DeLencastre et al. 2005). Thus, the structure of D5 and J2/3 in the O.i. intron is likely to be maintained throughout both steps of splicing (DeLencastre et al. 2005).

\section{Implications for structural features of the spliceosome}

The spliceosome contains a highly conserved 5'-AGC triad in U6 snRNA (Madhani and Guthrie 1992; Griffiths-Jones et al. 2005; Davila Lopez et al. 2008), much like the group IIA and IIB introns. Indeed, the conservation of this triad, together with similarities in branching mechanism, splice sites, and the stereochemical course of reaction, formed a strong case linking group II introns with the spliceosome (Yu et al. 1995; Villa et al. 2002; Butcher and Brow 2005).

Before attempting to make structural parallels between the spliceosome and the group IIC intron that has been crystallized (containing a 5'-CGC triad), it was important to use phylogenetic analysis and molecular modeling to determine if the structure of a $5^{\prime}$-AGC triad in group IIA and group IIB introns can be spatially accommodated within the active site that has been crystallized. An important clue for the modeling was that, in group II introns containing a $5^{\prime}$-CGC triad, the cognate nucleotide in $\mathrm{J} 2 / 3$ is a $\mathrm{C}$ (C289 in O.i.), while in introns containing a $5^{\prime}$ - AGC triad, the cognate nucleotide in $\mathrm{J} 2 / 3$ is an A (A589 in ai5 $\gamma$ ). Using this information, we modeled an $\mathrm{A} \bullet \mathrm{A}-\mathrm{U}$ triplet within the active site of the O.i. intron and subjected the hypothetical model to energy minimization (Fig. 5A,B). The alternative A•A-U triplet is readily accommodated within the O.i. active site and it forms a reasonable set of hydrogen bonding partners. 
A clear prediction for the triplet pairing by $5^{\prime}$-AGC introns was vital for spliceosomal comparisons because it enables one to predict the identity and location of the third-strand nucleotides that might interact with the $5^{\prime}$-AGC triad of U6. A molecular model for the interaction between D5 5'-AGC and J2/3 $5^{\prime}$-GA suggests several mutations that can be tested within spliceosomal systems. For example, one possibility is that nucleotides within the highly conserved 5'-ACAGAGA box in U6 (nucleotides 41-47 in the human sequence) interact in a manner similar to that of $\mathrm{J} 2 / 3$ (DeLencastre et al. 2005). Proximity between the conserved 5'-AGC and $5^{\prime}$-ACAGAGA sequences in U6 is consistent with previous work on spliceosomal systems (Madhani and Guthrie 1994; Valadkhan and Manley 2000). For most species, the $5^{\prime}$-ACAGAGA sequence contains two possible "GA" sequences that are available for interaction $\left(\mathrm{G}_{44} \mathrm{~A}_{45}\right.$ or $\mathrm{G}_{46} \mathrm{~A}_{47}$ ). While either pair could interact with the $5^{\prime}$-AGC, we think it is most likely that the downstream set $\left(\mathrm{G}_{46} \mathrm{~A}_{47}\right)$ participates in the triplex because the upstream set forms Watson-Crick base pairs with the $5^{\prime}$-splice site (KandelsLewis and Seraphin 1993; Lesser and Guthrie 1993). If GA nucleotides within the ACAGAGA box participate in triplex formation, it may be possible to make mutations in the U6 stem and corresponding suppressor mutations within the 5'-ACAGAGA box (Fig. 7C). One possibility would be to mutate the U6 triad to $5^{\prime}$-CGC and to evaluate whether corresponding to a $5^{\prime}$-ACAGAGC mutation suppresses splicing defects. Alternatively, other regions of U6 or perhaps even a peptide of Prp8, may form Hoogsteen interactions with the major-groove edge of nucleotides in the triad, resulting in a triplex and bulge architecture similar to that of group II introns. Once implicated by crosslinking or other methods, these residues could be mutated and tested for suppressive effects.

Another triplet that can be phylogenetically and genetically tested in the spliceosome is the third one, in which the triplet nucleobase is contributed by the D5 bulge $(\mathrm{C} \cdot \mathrm{C}-\mathrm{G})$ (Fig. 7C). The bulge of U6 binds metal ions (Yean et al. 2000; Blad et al. 2005), and is located five base pairs from the triad, just as in group II introns (Yu et al. 1995). The bulge nucleotides in U6 are frequently $5^{\prime}-\mathrm{A}_{73} \mathrm{U}_{74}$ (Griffiths-Jones et al. 2005; Davila Lopez et al. 2008 ), just as the bulge sequence in group II introns is often

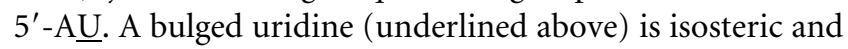
tolerated at this position because it forms an identical triplet to that of cytidine, through the $\mathrm{O} 2$ ketone moiety (Fig. 4A). Thus, the spliceosomal bulge is likely to interact with the catalytic triad in a similar manner (Fig. 7C). This model is consistent with genetic studies on the cognate uridine in U6 (U74 in humans, U80 in yeast), which demonstrate that this residue cannot be deleted or mutated to $\mathrm{G}$, but cytidine (and also adenine) are tolerated (Fabrizio and Abelson 1992; McPheeters and Abelson 1992).

The structural role of the adenosine nucleotide (A73) in the U6 bulge may also be analogous to the corresponding residue in group II introns. In the O.i. group II intron, bulge base A376 stacks on the invariant G5 residue in a manner predicted by site-directed photocrosslinking (DeLencastre et al. 2005). Similarly, spliceosomal introns also contain a conserved G5 residue that may stack on the conserved A in the bulge of U6. This may be contraindicated by genetic studies showing that spliceosomal G5 is part of a duplex formed with U6 sequences (Lesser and Guthrie 1993). However, it will be interesting to employ crosslinking or other methods to determine whether the spliceosomal G5 and U6 bulge nucleotides form a stacking network.

Another interaction that may provide insights into spliceosomal catalysis is a Hoogsteen-sugar-edge pairing between an invariant guanosine located beneath the D5 bulge and the highly conserved adenosine within the I(i) 
loop (the G378-A260 pairing in the O.i. structure). Similarly, spliceosomal U6 contains an almost invariant guanosine at the analogous position beneath the bulge (G75 is 99\% conserved) (Fig. 7C; Griffiths-Jones et al. 2005; Davila Lopez et al. 2008). The striking conservation and location of these residues suggests major mechanistic importance, but an extension to the spliceosome will await determination of an I(i) structural cognate in that system.

\section{Conclusions}

The recent crystal structure of the O.i. intron is strikingly consistent with over two decades of biochemical, genetic, and phylogenetic analysis on other group II intron families. It is therefore likely to reflect features of a universal and ancient group II intron core. Given that group II introns are believed to share an evolutionary heritage with the spliceosome, the structure may provide a useful map for designing structure-function studies on the spliceosomal active site. Preliminary comparative analysis of the group II intron structure with known features of U6 snRNA suggests that the two systems share many features in common.

\section{ACKNOWLEDGMENTS}

We gratefully acknowledge Magda Konarska, Olga Fedorova, Saba Valadkhan, and Sam Butcher for helpful discussions, and Michael Roitzsch for contribution of Figure 1 (unpublished). This work was supported by NIH grant GM RO150313 to A.M.P., and by the Howard Hughes Medical Institute. A.M.P. is an Investigator and N.T. is an Associate of the Howard Hughes Medical Institute. P.S.P is a Senior Science Officer of the Howard Hughes Medical Institute.

Received June 23, 2009; accepted August 12, 2009.

\section{REFERENCES}

Abramovitz DL, Friedman RA, Pyle AM. 1996. Catalytic role of 2 '-hydroxyl groups within a group II intron active site. Science 271: 1410-1413.

Barre FX, Ait-Si-Ali S, Giovannangeli C, Luis R, Robin P, Pritchard LL, Helene C, Harel-Bellan A. 2000. Unambiguous demonstration of triple-helix-directed gene modification. Proc Natl Acad Sci 97: 3084-3088.

Blad H, Reiter NJ, Abildgaard F, Markley JL, Butcher SE. 2005. Dynamics and metal ion binding in the U6 RNA intramolecular stem-loop as analyzed by NMR. J Mol Biol 353: 540-555.

Boeke JD. 2003. The unusual phylogenetic distribution of retrotransposons: A hypothesis. Genome Res 13: 1975-1983.

Boulanger SC, Belcher SM, Schmidt U, Dib-Hajj SD, Schmidt T, Perlman PS. 1995. Studies of point mutants define three essential paired nucleotides in the domain 5 substructure of a group II intron. Mol Cell Biol 15: 4479-4488.

Brünger AT, Adams PD, Clore GM, DeLano WL, Gros P, GrosseKunstleve RW, Jiang JS, Kuszewski J, Nilges M, Pannu NS, et al. 1998. Crystallography \& NMR system: A new software suite for macromolecular structure determination. Acta Crystallogr D 54: 905-921.

Butcher SE, Brow DA. 2005. Towards understanding the catalytic core structure of the spliceosome. Biochem Soc Trans 33: 447-449.
Centron D, Roy P. 2002. Presence of a group II intron in a multiresistant Serratia marcescens strain that harbors three integrons and a novel gene fusion. Antimicrob Agents Chemother 46: 14021409.

Chanfreau G, Jacquier A. 1994. Catalytic site components common to both splicing steps of a group II intron. Science 266: 1383-1387.

Costa M, Christian EL, Michel F. 1998. Differential chemical probing of a group II self-splicing intron identifies bases involved in tertiary interactions and supports an alternative secondary structure model of domain V. RNA 4: 1055-1068.

Davila Lopez M, Rosenblad MA, Samuelsson T. 2008. Computational screen for spliceosomal RNA genes aids in defining the phylogenetic distribution of major and minor spliceosomal components. Nucleic Acids Res 36: 3001-3010.

Davis IW, Leaver-Fay A, Chen VB, Block JN, Kapral GJ, Wang X, Murray LW, Arendall WB, 3rd, Snoeyink J, Richardson JS, et al. 2007. MolProbity: All-atom contacts and structure validation for proteins and nucleic acids. Nucleic Acids Res 35: W375-383.

DeLencastre A, Hamill S, Pyle AM. 2005. A single active-site region for a group II intron. Nat Struct Mol Biol 12: 626-627.

Diviacco S, Rapozzi V, Xodo L, Helene C, Quadrifoglio F, Giovannangeli C. 2001. Site-directed inhibition of DNA replication by triple helix formation. FASEB J 15: 2660-2668.

Duarte CM, Wadley LM, Pyle AM. 2003. RNA structure comparison, motif search and discovery using a reduced representation of RNA conformational space. Nucleic Acids Res 31: 4755-4761.

Emsley P, Cowtan K. 2004. Coot: Model-building tools for molecular graphics. Acta Crystallogr D 60: 2126-2132.

Fabrizio P, Abelson J. 1992. Thiophosphates in yeast U6 snRNA specifically affect pre-mRNA splicing in vitro. NAR 20: 3659-3664.

Frank-Kamenetskii MD, Mirkin SM. 1995. Triplex DNA structures. Annu Rev Biochem 64: 65-95.

Franzen JS, Zhang M, Peebles CL. 1993. Kinetic analysis of the $5^{\prime}$-splice junction hydrolysis of a group II intron promoted by domain 5. Nucleic Acids Res 21: 627-634.

Gilbert DE, Feigon J. 1999. Multistranded DNA structures. Curr Opin Struct Biol 9: 305-314.

Gilbert SD, Rambo RP, Van Tyne D, Batey RT. 2008. Structure of the SAM-II riboswitch bound to S-adenosylmethionine. Nat Struct Mol Biol 15: 177-182.

Gordon PM, Piccirilli JA. 2001. Metal ion coordination by the AGC triad in domain 5 contributes to group II intron catalysis. Nat Struct Biol 8: 893-898.

Granlund M, Michel F, Norgren M. 2001. Mutually exclusive distribution of IS1548 and GBSi1, an active group II intron identified in human isolates of group B streptococci. J Bacteriol 183: 2560-2569.

Gregan J, Kolisek M, Schweyen RJ. 2001. Mitochondrial $\mathrm{Mg}^{2+}$ homeostasis is critical for group II intron splicing in vivo. Genes \& Dev 15: 2229-2237.

Griffiths-Jones S, Moxon S, Marshall M, Khanna A, Eddy SR, Bateman A. 2005. Rfam: Annotating noncoding RNAs in complete genomes. Nucleic Acids Res 33: D121-D124.

Jarrell K, Dietrich R, Perlman P. 1988. Group II intron domain 5 facilitates a trans-splicing reaction. Mol Cell Biol 8: 2361-2366.

Jones JP 3rd, Kierlin MN, Coon RG, Perutka J, Lambowitz AM, Sullenger BA. 2005. Retargeting mobile group II introns to repair mutant genes. Mol Ther 11: 687-694.

Kandels-Lewis S, Seraphin B. 1993. Role of U6 snRNA in 5' -splice site selection. Science 262: 2035-2039.

Keating KS, Toor N, Pyle AM. 2008. The GANC tetraloop: A novel motif in the group IIC intron structure. J Mol Biol 383: 475481.

Kim NK, Zhang Q, Zhou J, Theimer CA, Peterson RD, Feigon J. 2008. Solution structure and dynamics of the wild-type pseudoknot of human telomerase RNA. J Mol Biol 384: 1249-1261.

Klein DJ, Moore PB, Steitz TA. 2004. The roles of ribosomal proteins in the structure assembly, and evolution of the large ribosomal subunit. J Mol Biol 340: 141-177. 
Koch JL, Boulanger SC, Dib-Hajj SD, Hebbar SK, Perlman PS. 1992. Group II introns deleted for multiple substructures retain selfsplicing activity. Mol Cell Biol 12: 1950-1958.

Konforti BB, Abramovitz DL, Duarte CM, Karpeisky A, Beigelman L, Pyle AM. 1998. Ribozyme catalysis from the major groove of group II intron domain 5. Mol Cell 1: 433-441.

Koonin EV. 2006. The origin of introns and their role in eukaryogenesis: A compromise solution to the introns-early versus intronslate debate? Biol Direct 1: 22. doi: 10.1186/1745-6150-1-22.

Lambowitz AM, Zimmerly S. 2004. Mobile group II introns. Annu Rev Genet 38: 1-35.

Lehmann K, Schmidt U. 2003. Group II introns: Structure and catalytic versatility of large natural ribozymes. Crit Rev Biochem Mol Biol 38: 249-303.

Leontis NB, Stombaugh J, Westhof E. 2002. The non-Watson-Crick base pairs and their associated isostericity matrices. Nucleic Acids Res 16: 3497-3531.

Lesser CF, Guthrie C. 1993. Mutations in U6 snRNA that alter splice site specificity: Implications for the active site. Science 262: 19821988.

Madhani HD, Guthrie C. 1992. A novel base-pairing interaction between U2 and U6 snRNAs suggests a mechanism for the catalytic activation of the spliceosome. Cell 71: 803-817.

Madhani HD, Guthrie C. 1994. Randomization-selection analysis of snRNAs in vivo: Evidence for a tertiary interaction in the spliceosome. Genes \& Dev 8: 1071-1086.

Mattick JS. 1994. Introns: Evolution and function. Curr Opin Genet Dev 4: 823-831.

Mattick JS, Gagen MJ. 2001. The evolution of controlled multitasked gene networks: The role of introns and other noncoding RNAs in the development of complex organisms. Mol Biol Evol 18: 16111630.

McPheeters DS, Abelson J. 1992. Mutational analysis of the yeast U2 snRNA suggests a structural similarity to the catalytic core of Group I introns. Cell 71: 819-831.

Michel F, Jacquier A, Dujon B. 1982. Comparison of fungal mitochondrial introns reveals extensive homologies in RNA secondary structure. Biochimie 64: 867-881.

Michel F, Umesono K, Ozeki H. 1989. Comparative and functional anatomy of group II catalytic introns-a review. Gene 82: 5-30.

Mikheeva S, Murray HL, Zhou H, Turczyk BM, Jarrell KA. 2000. Deletion of a conserved dinucleotide inhibits the second step of group II intron splicing. RNA 6: 1509-1515.

Mirkin SM, Frank-Kamenetskii MD. 1994. H-DNA and related structures. Annu Rev Biophys Biomol Struct 23: 541-576.

Murray LW. 2007. "RNA backbone rotamers and chiropraxis." $\mathrm{PhD}$ thesis, Duke University, Durham, NC.

Patel DJ, Radhakrishnan I. 1994. DNA triplexes: Solution structures, hydration sites, energetics, interactions, and function. Biochemistry 33: 11405-11416.

Peebles CL, Zhang M, Perlman PS, Franzen JF. 1995. Identification of a catalytically critical trinucleotide in domain 5 of a group II intron. Proc Natl Acad Sci 92: 4422-4426.

Pyle AM, Lambowitz AM. 2006. Group II introns: Ribozymes that splice RNA and invade DNA. In The RNA world (ed. R Gesteland et al.), pp. 469-506. Cold Spring Harbor Press, Cold Spring Harbor, NY.

Rest JS, Mindell DP. 2003. Retroids in archaea: Phylogeny and lateral origins. Mol Biol Evol 20: 1134-1142.

Rhee S, Han Z, Liu K, Miles HT, Davies DR. 1999. Structure of a triple helical DNA with a triplex-duplex junction. Biochemistry 38: 16810-16815.
Rogers FA, Lloyd JA, Glazer PM. 2005. Triplex-forming oligonucleotides as potential tools for modulation of gene expression. Curr Med Chem Anticancer Agents 5: 319-326.

Saenger W. 1984. Principles of nucleic acid structure. In Springer advanced texts in chemistry (ed. CR Cantor), Chap. 10, pp. 242252. Springer, New York.

Sarver M, Zirbel CL, Stombaugh J, Mokdad A, Leontis NB. 2008. FR3D: Finding local and composite recurrent structural motifs in RNA 3D structures. J Math Biol 56: 215-252.

Sashital DG, Cornilescu G, McManus CJ, Brow DA, Butcher SE. 2004. U2-U6 RNA folding reveals a group II intron-like domain and a four-helix junction. Nat Struct Mol Biol 11: 1237-1242.

Schmidt U, Maue I, Lehmann K, Belcher SM, Stahl U, Perlman PS. 1998. Mutant alleles of the MRS2 gene of yeast nuclear DNA suppress mutations in the catalytic core of a mitochondrial group II intron. J Mol Biol 282: 525-541.

Shukla GC, Padgett RA. 2002. A catalytically active group II intron domain 5 can function in the U12-dependent spliceosome. Mol Cell 9: 1145-1150.

Sigel RK, Sashital DG, Abramovitz DL, Palmer AG, Butcher SE, Pyle AM. 2004. Solution structure of domain 5 of a group II intron ribozyme reveals a new RNA motif. Nat Struct Mol Biol 11: 187-192.

Sun JS, Manley JL. 1995. A novel U2-U6 snRNA structure is necessary for splicing. Genes \& Dev 9: 843-854.

Sun JS, Garestier T, Helene C. 1996. Oligonucleotide directed triple helix formation. Curr Opin Struct Biol 6: 327-333.

Theimer CA, Blois CA, Feigon J. 2005. Structure of the human telomerase RNA pseudoknot reveals conserved tertiary interactions essential for function. Mol Cell 17: 671-682.

Toor N, Hausner G, Zimmerly S. 2001. Coevolution of group II intron RNA structures with their intron-encoded reverse transcriptases. RNA 7: 1142-1152.

Toor N, Keating KS, Taylor SD, Pyle AM. 2008a. Crystal structure of a self-spliced group II intron. Science 320: 77-82.

Toor N, Rajashankar K, Keating KS, Pyle AM. 2008b. Structural basis for exon recognition by a group II intron. Nat Struct Mol Biol 15: $1221-1222$.

Toor N, Keating KS, Pyle AM. 2009. Structural insights into RNA splicing. Curr Opin Struct Biol 19: 260-266.

Toor N, Keating KS, Fedorova O, Rajashankar K, Wang J, Pyle AM. 2010. Tertiary architecture of the Oceanobacillus iheyensis group II intron. RNA (this issue). doi: 10.1261/rna.1844010.

Valadkhan S, Manley JL. 2000. A tertiary interaction detected in a human U2-U6 snRNA complex assembled in vitro resembles a genetically proven interaction in yeast. RNA 6: 206-219.

Villa T, Pleiss JA, Guthrie C. 2002. Spliceosomal snRNAs: $\mathrm{Mg}^{2+}$ dependent chemistry at the catalytic core? Cell 109: 149-152.

Wadley LM, Keating KS, Duarte CM, Pyle AM. 2007. Evaluating and learning from RNA pseudotorsional space: Quantitative validation of a reduced representation for RNA structure. J Mol Biol 372: 942-957.

Wheelan SJ, Aizawa Y, Han JS, Boeke JD. 2005. Gene-breaking: A new paradigm for human retrotransposon-mediated gene evolution. Genome Res 15: 1073-1078.

Yean SL, Wuenschell G, Termini J, Lin RJ. 2000. Metal-ion coordination by $\mathrm{U} 6$ small nuclear RNA contributes to catalysis in the spliceosome. Nature 408: 881-884.

Yu Y-T, Maroney PA, Darzynkiewicz E, Nilsen TW. 1995. U6 snRNA function in nuclear pre-mRNA splicing: A phosphorothioate interference analysis of the U6 phosphate backbone. RNA 1: 46-54.

Zhang L, Doudna JA. 2002. Structural insights into group II intron catalysis and branch-site selection. Science 295: 2084-2088. 

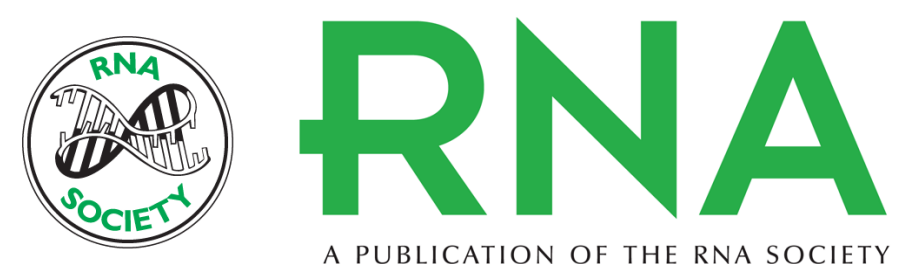

A PUBLICATION OF THE RNA SOCIETY

\section{A structural analysis of the group II intron active site and implications for the spliceosome}

Kevin S. Keating, Navtej Toor, Philip S. Perlman, et al.

RNA 2010 16: 1-9 originally published online November 30, 2009

Access the most recent version at doi:10.1261/rna.1791310

References This article cites 72 articles, 24 of which can be accessed free at: http://rnajournal.cshlp.org/content/16/1/1.full.htmI\#ref-list-1

Open Access Freely available online through the RNA Open Access option.

License Freely available online through the RNA Open Access option.

Email Alerting Receive free email alerts when new articles cite this article - sign up in the box at the Service top right corner of the article or click here. 